\title{
Characterisation of a multimeric protein complex associated with ERp57 within the nucleus in paclitaxel-sensitive and -resistant epithelial ovarian cancer cells: The involvement of specific conformational states of $B$-actin
}

\author{
LUCIA CICCHILLITTI $^{1}$, ANNA DELLA CORTE $^{2}$, MICHELA DI MICHELE $^{2}$, MARIA BENEDETTA DONATI $^{2}$, \\ DOMENICO ROTILIO $^{2}$ and GIOVANNI SCAMBIA ${ }^{1}$ \\ ${ }^{1}$ Department of Oncology, ${ }^{2}$ Laboratory of Analytical Techniques and Proteomics, Research Laboratories, \\ Catholic University, Largo A. Gemelli 1, I-86100 Campobasso, Italy
}

Received December 23, 2009; Accepted January 28, 2010

DOI: 10.3892/ijo_00000693

\begin{abstract}
Ovarian cancer is the second most frequently diagnosed malignancy of the reproductive system and is the leading cause of gynecological cancer mortality. Although the majority of advanced ovarian carcinomas initially respond successfully to taxane-based chemotherapy, resistance to chemotherapy remains the primary factor accounting for the low 5-year survival in this patient population. Recent data obtained by our group demonstrate that the disulphide isomerase ERp57 is strongly modulated in paclitaxel resistance suggesting that it may represent a chemoresistance biomarker in ovarian cancer. In the present study, we characterise a nuclear multimeric complex where ERp57 is associated with protein species involved in cell division and gene expression, as Nucleolin, Nucleophosmin, Vimentin, Aurora kinase C and $B$-actin. In particular, we show that the occurrence of the interaction of nuclear ERp57 with $\beta$-actin is associated with paclitaxel resistance and that specific actin conformations modulate this complex. We propose the involvement of the nuclear ERp57 complex in mechanisms associated with chromosome segregation in which specific conformational states of actin play a role in the pathway involved in paclitaxel resistance.
\end{abstract}

Correspondence to: Dr Lucia Cicchillitti, Department of Oncology, Catholic University, Largo A. Gemelli 1, I-86100 Campobasso, Italy

E-mail: luciacic@yahoo.com

Abbreviations: 2-DE, two-dimensional polyacrylamide gel electrophoresis; ER, endoplasmic reticulum; MALDI-TOF, matrixassisted laser desorption/ionization time-of-flight; NEM, N-ethylmaleimide; HRP, horseradish peroxidase; TUBB3, class III ß-tubulin

Key words: ERp57, chemoresistance, mass spectrometry, ovarian cancer, paclitaxel

\section{Introduction}

Epithelial ovarian carcinoma is a major cause of death among gynecological malignancies (1). Treatment of ovarian cancer consists of optimal debulking surgery combined with platinumtaxane combination chemotherapy. Treatment of ovarian cancer is difficult because of both the inability to completely remove surgically diffuse tumor involvement on the peritoneal surface and the possible resistance of the tumor cells to chemotherapy. Drug resistance represents a pleiotropic phenomenon characterised by changes in expression and function of several strictly interconnected proteins. Several mechanisms have been implicated in paclitaxel resistance, such as the selective expression of $\beta$-tubulin isotypes and the overexpression of P-glycoprotein (2), however the overall molecular mechanisms remain to be elucidated. To better understand molecular resistance mechanisms, in previous studies based on differential in gel electrophoresis (DIGE) coupled with mass spectrometry analysis we identified several proteins differently modulated in paclitaxel-sensitive as compared to -resistant human epithelial ovarian cancer cells that could represent chemoresistance biomarkers. These proteins were grouped into main functional classes. Most of the proteins were related to the category of stress response and chaperones suggesting that alterations of those processes might be involved in paclitaxel resistance $(3,4)$. Recent studies identified ERp57, a chaperone belonging to the disulphide isomerase family involved in the correct folding of proteins, as a plausible therapeutic target in ovarian cancer. In fact, ERp57 gene was found to be associated with drug resistance in a study based on an array comparative genomic hybridization (aCGH) and microarray expression profiling in epithelial ovarian cancer tissues (5). Furthermore, we have recently suggested a role of ERp57 protein in pathways that regulate the sensitivity of ovarian cancer to paclitaxel and identified it as a plausible candidate for treatment response biomarker (3).

ERp57, also known as PDIA3, GRP58, ERp60 and ERp61, has been suggested to act as a cysteine-dependent protease (6), a carnitine palmitoyltransferase (7), and a thiol-dependent reductase $(8,9)$, but its precise function remains to be estab- 
lished. Consistent with its thiol-dependent reductase activity is the presence of two WCGHCK motifs identical to those found in PDI and ERp72, and very similar to those in thioredoxin (10). Though mainly localised in the endoplasmic reticulum (ER), where it acts in concert with calnexin and calreticulin to modulate glycoprotein folding and enforce the glycoprotein specific quality control mechanism, ERp57 has also been found in the cytosol and in the nucleus. In the cytosol it is involved in signal transduction and transcription regulation by activation of STAT3 (11) and associated with a sodium chloride cotransporter (12), while in the nucleus it influences the DNA binding of transcription factors or of structural nuclear proteins by chemically cross-linking DNA sequences (13). We have previously characterised the ERp57 ability to bind to a specific B-tubulin isotype, TUBB3, overexpressed in paclitaxel-resistant cells and identified as a clinical marker of drug resistance in ovary $(14,15)$, and to several nuclear proteins required for the correct kinetocore-microtubule attachments (3). Interestingly, in the above-mentioned study it was observed that the ERp57/TUBB3 complex was prominent in paclitaxel-resistant A2780TC1 cells compared to sensitive cells thus suggesting a role of this protein in the regulation of the association between microtubules and kinetochore and in the cellular response to paclitaxel treatment.

Actin is a major component of the cytoskeleton and plays a critical role in all eukaryotic cells. In mammals at least six actin isoforms are encoded by separate genes, and are divided into $\alpha, \beta$, and $\gamma$, according to their isoelectric point. In general, the $\beta$ isoform is predominant in non-muscle cells. The actin cytoskeleton functions in diverse cellular processes, including cell motility, contractility, mitosis and cytokinesis, intracellular transport, endocytosis and secretion $(16,17)$. In addition to these mechanical functions, actin has also been implicated in the regulation of gene transcription, through either cytoplasmic changes in cytoskeletal actin dynamics (18) or the assembly of transcriptional regulatory complexes (19). Monomeric, oligomeric or polymeric forms of actin seem to be involved in nuclear functions. The presence of actin within the nucleus was first suggested in 1969 (20), but its role in the nucleus has been extremely controversial. One of the first demonstrations of a role for actin in the nucleus was as a collaborating factor in chromatin remodelling (21), an idea that has been increasingly confirmed and extended (22-25).

In this review we confirmed the presence of ERp57 in the nucleus and characterised its nuclear protein partners in A2780 and A2780TC1 cells. We identified a multimeric nuclear complex containing ERp57, Nucleolin, Nucleophosmin, Aurora kinase $C$, Vimentin and $B$-actin. In particular, we observed that the occurrence of $B$-actin interaction with the ERp57 nuclear complex is associated with paclitaxel resistance. Moreover, we describe that the nuclear ERp57/ß-actin complex is modulated by specific conformational states of actin and that the occurrence of this interaction is less prominent in paclitaxel-resistant cells compared to sensitive cells thus suggesting its involvement and modulation in drug resistance pathways.

Understanding the molecular mechanism involved in the formation of nuclear ERp57/ß-actin complex in ovarian cancer cells might favour the development of novel therapeutic approaches to overcome chemoresistance occurrence.

\section{Materials and methods}

Chemicals and reagents. General chemicals were obtained from Sigma-Aldrich (Poole, UK), Bradford assay kit was from Bio-Rad (Hercules, CA, USA). Anti-ERp57 monoclonal antibody (sc-23886) and anti-actin polyclonal (sc-10731) antibodies were obtained from Santa Cruz Biotechnology (Santa Cruz, CA); anti-ß-actin monoclonal antibody (A1978) was purchased from Sigma Aldrich (Poole, UK); anti-TUBB3 polyclonal antibody (PRB-435P) was purchased from Covance (CA, USA); anti-actin monoclonal antibodies 1C7 and 2G2 were obtained from Technical University of Braunschweig, Germany. Potassium ferricyanide, sodium thiosulfate, trypsin, and $\alpha$-cyano-4-hydroxycinnamic acid were purchased from Sigma as acetonitrile and TFA which were for mass spectrometry use. Chemicals and biochemicals used were of analytical grade.

Cell lines and paclitaxel cytotoxicity. The human ovarian cancer cell line A2780 was purchased from the European Collection of Cell Cultures (Salisbury, UK). A2780TC1 was previously produced by our group and is a cell clone derived from A2780 cells chronically exposed to paclitaxel (100 nmol/l). Growth conditions and paclitaxel toxicity testing were the same as previously described (26). In all experiments, in order to ensure data reproducibility, A2780TC1 cells were cultured in the absence of paclitaxel for two passages before each experiment.

Immunoblotting of the subcellular fractions. Cells, harvested in cold phosphate-buffered saline, were extracted for $30 \mathrm{~min}$ at $4^{\circ} \mathrm{C}$ in lysis buffer (50 mM Tris- $\mathrm{HCl}, \mathrm{pH} 7.4,150 \mathrm{mM} \mathrm{NaCl}$, $1 \%$ NP-40) containing $1 \mathrm{mM}$ DTT, protease inhibitor cocktail (Roche) and phosphatase inhibitors (50 mM NaF, $0.2 \mathrm{mM}$ $\mathrm{Na}_{3} \mathrm{VO}_{4}$ ) or treated with $25 \mathrm{mM} \mathrm{N}$-ethylmaleimide (NEM) for $5 \mathrm{~min}$ before harvesting to preserve mixed disulphides. After centrifugation, supernatants were collected as the total protein extract and stored at $-80^{\circ} \mathrm{C}$. Nuclear lysates were obtained as previously described (3). Briefly, 30x10 $10^{6}$ of cells were scraped, rinsed with phosphate-buffered saline, lysed on ice for $10 \mathrm{~min}$ with $3 \mathrm{ml}$ of hypotonic buffer (10 mM HEPES, $\mathrm{pH}$ 8.0, $40 \mathrm{mM} \mathrm{KCl}, 3 \mathrm{mM} \mathrm{MgCl} 2,5 \%$ glycerol, $2 \mathrm{mM}$ DTT) with the addition of $0.5 \%$ NP-40 to facilitate cells lysis, supplemented with a protease inhibitor cocktail (Roche). Nuclei were pelletted performing high-speed centrifugation $\left(6,000 \mathrm{rpm}\right.$ for $10 \mathrm{~min}$ at $\left.4^{\circ} \mathrm{C}\right)$, washed twice with hypotonic buffer and resuspended with $300 \mu \mathrm{l}$ of nuclei lysis buffer (10 mM HEPES, pH 8.0, $420 \mathrm{mM} \mathrm{NaCl}, 1.5 \mathrm{mM} \mathrm{MgCl}_{2}$, $25 \%$ glycerol, and $0.5 \mathrm{mM}$ DTT) on ice for $10 \mathrm{~min}$. After centrifugation $\left(6,000 \mathrm{rpm}\right.$ for $10 \mathrm{~min}$ at $\left.4^{\circ} \mathrm{C}\right)$, the supernatant was collected as nuclear fraction and stored at $-80^{\circ} \mathrm{C}$. Protein concentrations were measured using the Bradford-type protein assay (Bio-Rad). To perform experiments represented in Fig. $3,30 \times 10^{6}$ of cells were lysed in $3 \mathrm{ml}$ of lysis buffer to prepare whole cell extracts. For immunoprecipitation experiments, nuclear lysates were clarified and immunoprecipitated at $4^{\circ} \mathrm{C}$ overnight in lysis buffer by adding protein A/G plus-agarose beads (Santa Cruz Biotechnology) after $2 \mathrm{~h}$ of incubation with $2 \mu \mathrm{g}$ of antibody. Proteins were resolved by $1-\mathrm{DE}$ or $2-\mathrm{DE}$ and electrotransferred to nitrocellulose 
membrane (Schleicher and Schuell GmbH, Germany). Each membrane was blocked with 5\% non-fat dry milk in Trisbuffered saline-Tween-20 (TBST) for $1 \mathrm{~h}$ at room temperature and subsequently incubated with primary antibody for $16 \mathrm{~h}$ at $4^{\circ} \mathrm{C}$. Immunoreactivity was detected by sequential incubation with HRP-conjugated secondary antibody. Immunoblots were developed using Supersignal West Femto chemiluminescent reagents (Pierce Biotechnology, Rockford, IL, USA).

2-DE. For two-dimensional polyacrylamide gel electrophoresis (2-DE) non-reduced/reduced analysis, proteins were mixed in non-reducing SDS-PAGE sample buffer [0.25 mM Tris-HCl $\mathrm{pH} 6.8,2 \%(\mathrm{w} / \mathrm{v})$ SDS, $20 \%(\mathrm{v} / \mathrm{v})$ glycerol, $0.004 \%(\mathrm{w} / \mathrm{v})$ bromophenol blue] and separated by SDS-PAGE on a $10 \%$ acrylamide gel. Gel lanes were excised and incubated in buffer containing $50 \mathrm{mM}$ DTT for $10 \mathrm{~min}$ and further $10 \mathrm{~min}$ in $100 \mathrm{mM}$ iodoacetamide (IAA) before separation through a second SDS-PAGE gel (10\%). For 2-DE analysis, proteins were dissolved in the isoelectric focusing solution, containing $8 \mathrm{M}$ urea, 4\% CHAPS, and 2\% carrier ampholyte $\mathrm{pH}$ 3.0-10. The IPG strips (pH 3.0-10 non-linear, 7 cm long, GE-Healthcare) were rehydrated with isoelectric focusing solution with $0.002 \%$ bromophenol blue containing protein sample and analysis carried out in a Ettan IPGphor II $^{\mathrm{TM}}$ (GE-Healthcare) for $12 \mathrm{~h}$ at $20^{\circ} \mathrm{C}$. The rehydrated strips were focused at $20^{\circ} \mathrm{C}$ using the following running conditions: $300 \mathrm{~V}$ for $4 \mathrm{~h}$, voltage gradient from 300 to $1,000 \mathrm{~V}$ in $1 \mathrm{~h}$, voltage gradient from 1,000 to $5,000 \mathrm{~V}$ in $2 \mathrm{~h}, 5,000 \mathrm{~V}$ for $40 \mathrm{~min}$. Before running the second dimension, the IPG strips were equilibrated for $15 \mathrm{~min}$ in equilibration buffer [6 $\mathrm{M}$ urea, $2 \%(\mathrm{w} / \mathrm{v})$ sodiumdodecyl sulphate (SDS), $50 \mathrm{mM}$ Tris- $\mathrm{HCl}$ buffer at $\mathrm{pH} 8.8$ and $30 \%(\mathrm{v} / \mathrm{v})$ glycerol] with $10 \mathrm{mg} / \mathrm{ml}$ DTT and for $15 \mathrm{~min}$ in equilibration buffer containing $25 \mathrm{mg} / \mathrm{ml}$ iodoacetamide. Electrophoresis in the second dimension was carried out in $10 \%$ polyacrylamide gels. The IPG strips were embedded with $0.5 \% \mathrm{w} / \mathrm{v}$ melted agarose solution, prior to running on the SDS-PAGE slabs.

In gel digestion and mass spectrometry. For spot picking, gels were fixed in $50 \%$ methanol/7\% acetic acid for $1 \mathrm{~h}$ followed by silver staining. Spots of interest were excised and reduced to small pieces. The gel pieces were destained by washing twice with $6 \mathrm{mM}$ potassium ferricyanide in $100 \mathrm{~g} / 1$ sodium thiosulfate and proteins digested overnight with $20 \mathrm{ng} / \mu 1$ trypsin (Sigma) in $40 \mathrm{mM}$ ammonium bicarbonate/10\% acetonitrile at $37^{\circ} \mathrm{C}$. The digestion reaction was blocked by adding $1 \%$ TFA. The proteolytic peptides were extracted with $50 \%$ acetonitrile/ $0.1 \%$ TFA, dried in a vacuum centrifuge and redissolved in $50 \%$ acetonitrile/ $0.1 \%$ TFA. The sample solution was mixed with matrix ( $\alpha$-cyano-4-hydroxycinnamic acid, $10 \mathrm{mg} / \mathrm{ml}$ in $50 \%$ ACN/0.1\% TFA acid) and spotted onto a MALDI target. Peptide mass fingerprinting was performed on a Voyager-DE STR MALDI-TOF mass spectrometer (Applied Biosystems, Stafford, USA), operating in positive ion reflectron mode, with an acceleration voltage of $20 \mathrm{kV}$, a nitrogen laser $(337 \mathrm{~nm})$ and a laser repetition rate of $4 \mathrm{~Hz}$. The final mass spectra, measured over a mass range of 800-3,000 Da and by averaging 50-200 laser shots, were finally analysed using the DataExplorer software v4.0 (Applied
Biosystem). All mass spectra were calibrated with a calibration kit (Applied Biosystem) and internally calibrated using trypsin autolysis digestion products. Mascot software (Matrix Science, London, UK) was employed for protein database searching. The searches were performed using the NCBI database and the following standard parameters: Homo sapiens; tryptic digest with a maximum of one missed cleavage; carboxyamidomethylation of cysteine, partial methionine oxidation and a mass tolerance of $100 \mathrm{ppm}$. A Mascot score of 64 corresponding to $\mathrm{p}<0.05$ for mass finger print experiments was chosen as the cut-off for a significant hit.

Chromatographic analysis. Chromatographic analysis was performed using the Q-proteome glycoprotein kit and the phosphoprotein purification kit purchased from Qiagen (GmbH, Germany).

\section{Results}

Erp57 is glycosylated and phosphorylated in paclitaxel-sensitive and -resistant $A 2780$ cells. It has already been shown that ERp57 is subjected to post-translational modifications such as glycosylation and phosphorylation (27-29). In order to better characterise ERp57 post-translational status in paclitaxelsensitive ovarian cancer cells A2780 and in its paclitaxelresistant counterpart, A2780TC1, we performed affinity chromatography studies. To assess the presence of ERp57 glycosylation in A2780 and A2780TC1 cells, glycoproteins were separated using affinity chromatography for Concanavalin A (Con A), Snowdrop (GNA) and Lentil (LCH) lectins and eluted proteins subjected to Western blotting using the antibody raised against ERp57. Con A recognizes $\alpha$-linked mannose and terminal glucose residues branched $\alpha$-mannosidic structures and high-mannose type, hybrid type and biantennary complex type N-Glycans; GNA lectin selectively binds to $\alpha 1-3$ and $\alpha 1-6$ linked high mannose moieties; $\mathrm{LCH}$ lectin has specificity for fucosylated core region of bi- and tri-antennary complex type N-Glycans. Results showed that ERp57 is glycosylated in both cell lines tested and that it has mannose rich glycan moieties, since it was able to bind to all three lectins used, but no differences in its glycosylation status were observed between A2780 and A2780TC1 cells (Fig. 1A). We also performed affinity chromatography studies for the specific purification of phosphorylated proteins from total cell lysates to evaluate the phosphorylation status of ERp57. Protein phosphorylation has been shown to cause a $\mathrm{pI}$ shift towards a more acidic $\mathrm{pH}$, detected as multiple spots observed on 2-DE gels. Eluted proteins from phospho-columns and whole cell lysates were separated on 2-DE gels followed by Western blot analysis using the anti-ERp57 antibody. The detection of a signal migrating in correspondence with the more negatively charged protein spots showed that ERp57 was also phosphorylated in A2780 and A2780TC1 cells (Fig. 1B).

Characterization of the nuclear ERp57 complex. ERp57 has different roles depending on its subcellular localisation. In a previous study we have demonstrated the ERp57 localization in the nucleus and its ability to associate with protein species involved in chromosome segregation and with a specific 
A

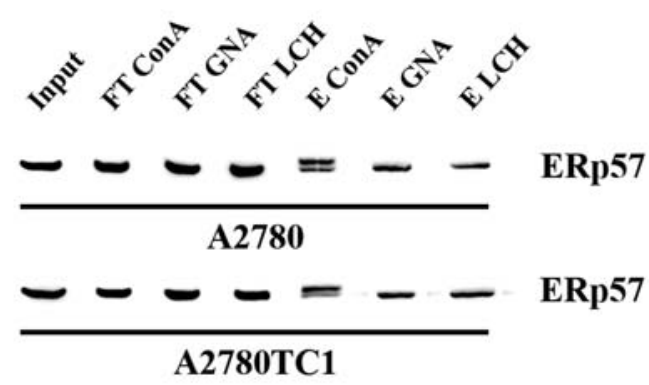

B

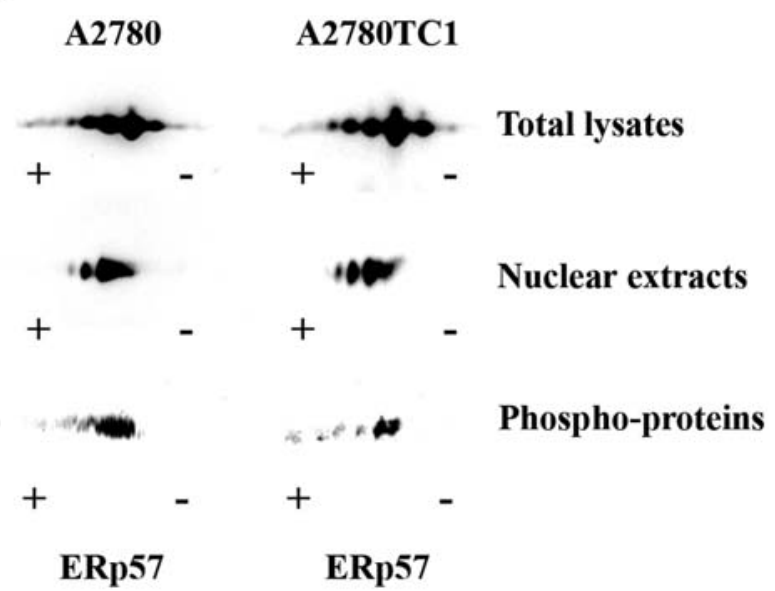

Figure 1. ERp57 is glycosylated and phosphorylated in paclitaxel-sensitive (A2780) and -resistant (A2780TC1) cells. (A) Western blotting with antiERp57 antibody after separation from total lysates of glycosylated (E) and unglycosylated (FT) proteins obtained from A2780 and A2780TC1 cells using Con A, GNA and LCH affinity columns. (B) Western blotting with anti-ERp57 antibody after 2-DE analysis carried out using total lysates, nuclear fractions, and phosphoproteins obtained after affinity chromatography procedure from A2780 and A2780TC1 cells.

TUBB3 isoform involved in mechanisms associated with paclitaxel resistance (3). In order to analyze ERp57 status in the nucleus, we performed 2-DE analysis using total lysates and nuclear fractions. As evinced by Western blotting approach, nuclear ERp57 was phosphorylated since protein spots detected by the specific ERp57 antibody migrated in correspondence with phosphorylated isoforms (Fig. 1B). These pieces of evidence indicate that post-translational modifications characterise ERp57 in A2780 cells and, in particular, that a specific kinase and/or phosphatase activity on ERp57 very likely modulates its localisation within the nucleus. To better characterise the role of ERp57 in the nuclear compartment, we performed immunoprecipitation analysis followed by 2-DE (Fig. 2) and identified by mass spectrometry the protein species associated with ERp57 using nuclear fractions obtained from A2780 and A2780TC1 cells as previously described (3). Five ERp57 protein interacting partners were successfully identified (Table I). With this experimental approach we were not able to identify TUBB3 among the protein species belonging to the nuclear ERp57 complex. We have to consider that TUBB3 has been reported to be an isotype-specific for neuronal tissues and testis and has generally very low level of expression in other tissues, thus probably explaining the lack of detection of TUBB3 in the nuclear ERp57 complex. However, the occurrence of ERp57/TUBB3 association within the nuclear compartment has been previously reported by our group using the specific antibody against TUBB3. The presence of TUBB3 in our nuclear preparations was confirmed by 2-DE and 1-DE analysis (Fig. 3) through which we were able to detect the presence of the specific nuclear slower migrating TUBB3 isoform found to be associated with ERp57 (3). In this study we confirmed the association of ERp57 with the previously identified protein species, Nucleophosmin and Nucleolin (3). These two proteins have been described as chromatin associated proteins with histone chaperone activities, as proteins able to regulate chromatin transcription and as genotoxic stress-responsive RNA-binding proteins $(30,31)$. Moreover, we were able to identify other novel protein partners, the serine/threonine kinase Aurora kinase C, Vimentin and B-actin. Aurora kinase C has been found to be over-expressed in some cancer cell lines including HepG2, HUH7, MDA-MB-453 and HeLa (32). It belongs to the Aurora protein kinase family (consisting of

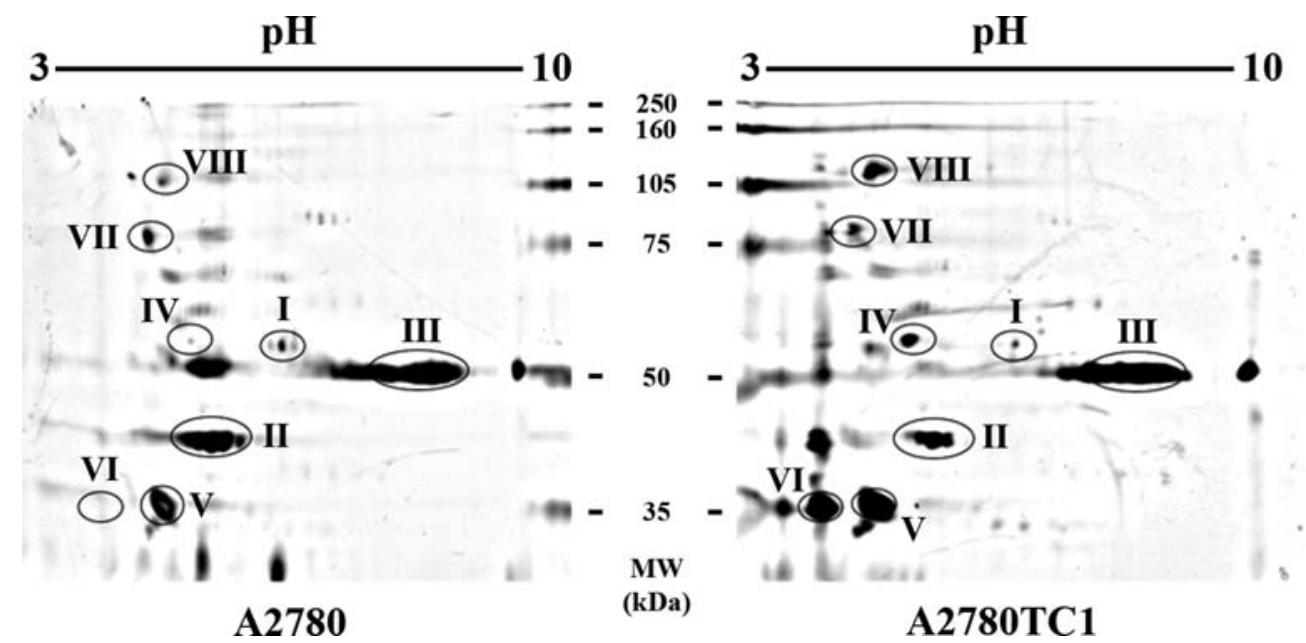

Figure 2. Characterization of nuclear ERp57 complexes. Proteins from nuclear extracts from A2780 and A2780TC1 cells were immunoprecipitated with anti-ERp57 antibody, resolved by 2-DE on a 7-cm, pH 3.0-10 NL strip followed by 10\% SDS-PAGE, silver stained and identified by MS. 
Table I. Proteins associated with ERp57 using nuclear fractions obtained from paclitaxel-sensitive (A2780) and -resistant (A2780TC1) cells: analysis by 2DE and identification by mass spectrometry.

\begin{tabular}{|c|c|c|c|c|c|c|c|}
\hline N. spot & Mascot code & Protein & Theoretical MW (Da) & Theoretical pI & Mascot score & Coverage $\%$ & Matches \\
\hline I & gi/119597640 & ERp57 & 54454 & 6.78 & 68 & 34 & $20 / 162$ \\
\hline II & $\mathrm{gi} / 14250401$ & Actin $\beta$ & 41321 & 5.56 & 71 & 36 & $12 / 72$ \\
\hline III & gi/62865641 & Aurora kinase $\mathrm{C}$ & 33936 & 8.97 & 78 & 53 & $19 / 218$ \\
\hline IV & gi/62414289 & Vimentin & 53676 & 5.06 & 281 & 67 & $46 / 145$ \\
\hline $\mathrm{V}$ & $\mathrm{gi} / 825671$ & Nucleophosmin & 31090 & 4.71 & 88 & 53 & $17 / 132$ \\
\hline VI & gi/825671 & Nucleophosmin & 31090 & 4.71 & 28 & 21 & $6 / 74$ \\
\hline VII & gi/119591368 & Nucleolin & 58576 & 4.57 & 66 & 23 & $14 / 81$ \\
\hline VIII & gi/119591368 & Nucleolin & 58576 & 4.57 & 66 & 32 & $17 / 129$ \\
\hline
\end{tabular}

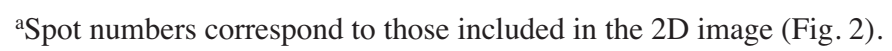

A

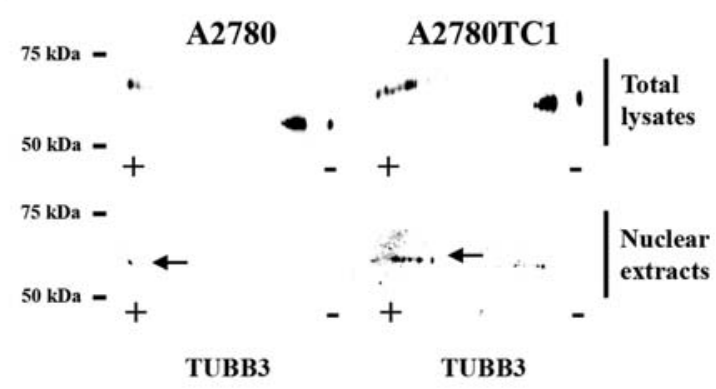

B

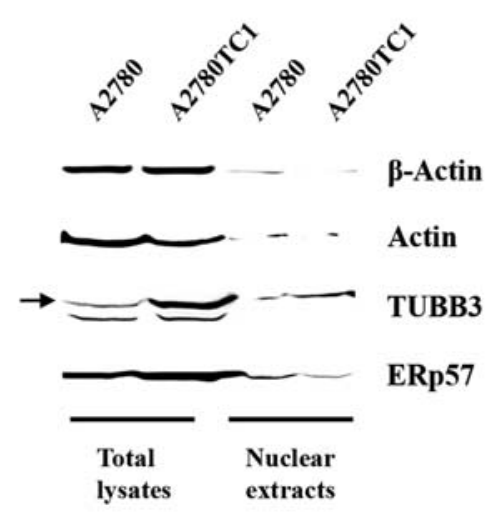

C

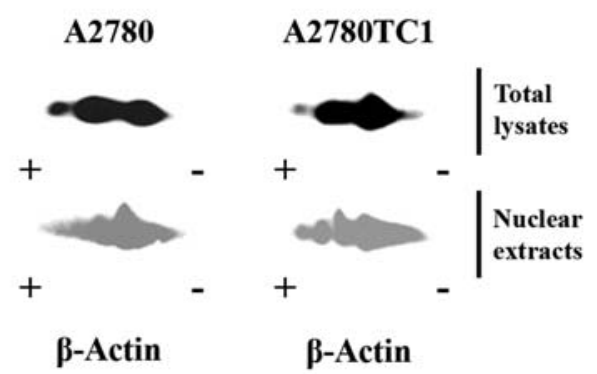

Figure 3. Analysis of TUBB3, ERp57 and B-actin protein expression levels in whole cell lysates and nuclear extracts obtained from A2780 and A2780TC1 cells. (A) 2-DE analysis followed by Western blot analysis with anti-TUBB3 antibody. (B) Western blotting with the polyclonal anti-actin, anti- $\beta$-actin, anti-TUBB3 and anti-ERp57 antibodies using whole cell lysates and nuclear fractions from A2780 and A2780TC1 cells after 1-DE. The arrows indicate the nuclear TUBB3 isoform. (C) 2-DE analysis followed by Western blotting with anti-B-actin antibody using proteins obtained from total $(100 \mu \mathrm{g})$ and nuclear extracts $(150 \mu \mathrm{g})$ from A2780 and A2780TC1 cells.
Aurora-A, -B and -C) that is an important group of enzymes that controls several aspects of cell division in mammalian cells (33-35). Aurora kinases are over-expressed in some gynecologic cancers, and their overexpression is associated with poor prognosis $(36,37)$. Vimentin is an intermediate filament protein involved, during mitosis, in the proper segregation of the filament in the daughter cells (38). B-actin is the isotype prevalently localised within the nucleus (39). Actin within the nucleus of living cells exists as a dynamic equilibrium of monomers and polymers involved in gene expression, mRNA processing and chromatin remodelling $(16,17)$. Moreover, Kwon et al showed that actin function is important for successful mitosis of cells carrying centrosome amplification (40). These data indicate the involvement of nuclear ERp57 in the pathways associated with cell division and cancer development.

Nuclear ERp57 interaction with $\beta$-actin is associated with paclitaxel resistance. We have previously suggested a role of ERp57 in the chromosome congression and in the regulation of the microtubules/kinetochore association where the specific slower migrating isoform of TUBB3, involved in ovarian cancer development and chemoresistance, plays a role. Since actin has been shown to have a role in the control of spindle polarity in association with microtubules (41), we focused our attention on the ERp57/ß-actin nuclear complex in order to investigate its possible involvement in the cellular response to paclitaxel treatment. Firstly, actin protein level in our nuclear extracts was analysed using the anti-actin polyclonal antibody, reacting with a broad range of actin isoforms, and the monoclonal antibody against B-actin. As shown in Fig. 3B, actin protein was barely detectable in the nuclear compartment. However, 2-DE analysis performed using large amount of nuclear lysates followed by Western blotting allowed us to detect the B-actin signal and confirmed its localization in the nucleus (Fig. 3C). We performed immunoisolation with the anti-ERp57 antibody followed by Western blotting using the antibody against $\beta$-actin with nuclear extracts (Fig. 4A). This analysis confirmed the occurrence of the interaction of ERp57 with B-actin within the nucleus and, interestingly, showed the prevalence of the ERp57/ß-actin complex in A2780 compared to its paclitaxel- 
A

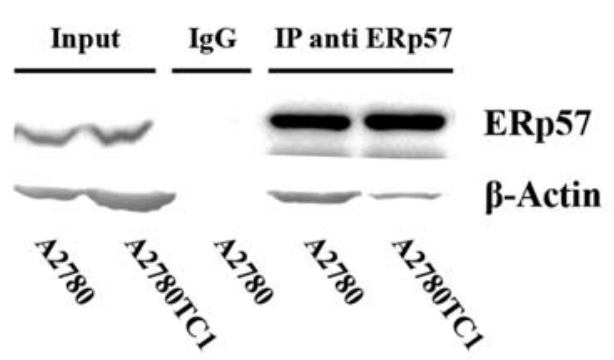

B

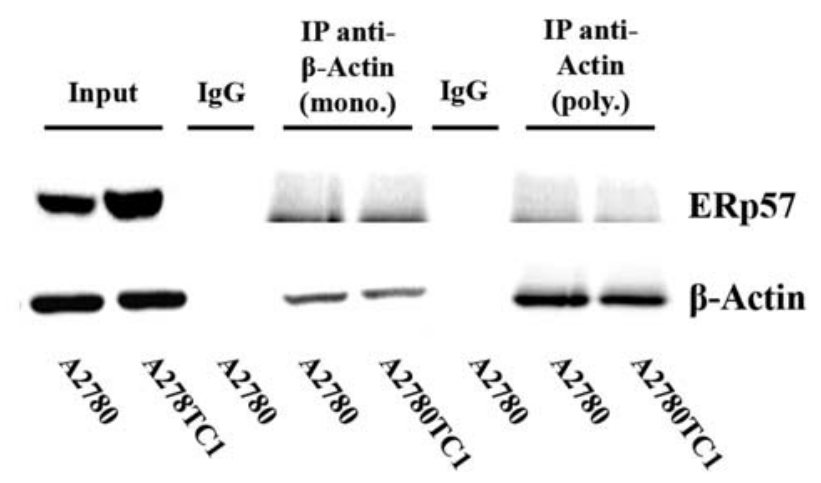

C

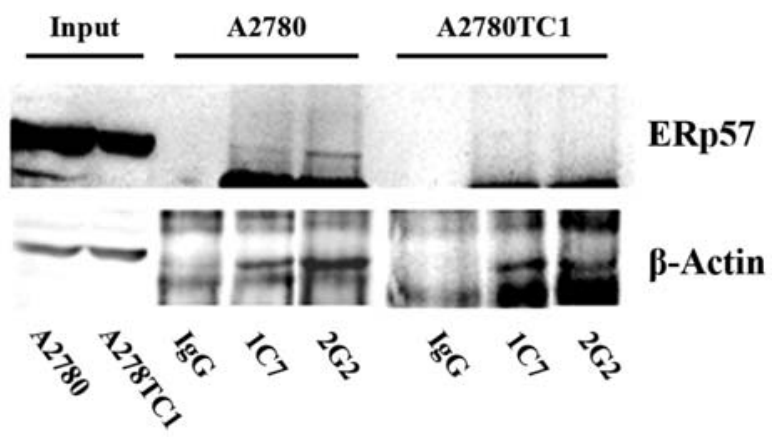

Figure 4. ERp57/ß-actin complex depends on specific actin conformations and is associated with paclitaxel resistance. (A) Western blot analysis using anti-ERp57 and anti- $\beta$-actin antibodies after immunoisolation (IP) of protein species from nuclear fractions with anti-ERp57 antibody. (B) Western blot analysis using anti-ERp57 and anti-ß-actin antibodies after immunoisolation (IP) of protein species from nuclear fractions with the monoclonal anti- $\beta$-actin antibody and the anti-actin polyclonal antibody, reacting with a broad range of actin isoforms. (C) Immunoprecipitation (IP) performed using nuclear extracts from A2780 and A2780TC1 cells with 1C7 and 2G2 anti-actin antibodies followed by Western blot analysis with anti-ß-actin and anti-ERp57 antibodies.

resistant counterpart A2780TC1. On the contrary, when we performed the co-immunoprecipitation analysis using both the anti- $\beta$-actin monoclonal and the anti-actin polyclonal antibodies followed by Western blotting, we were not able to detect any signal with the antibody specific for ERp57 (Fig. 4B). This result indicates that ERp57 and B-actin may not interact directly and/or other protein species interacting with actin or the anti-actin antibodies themselves may compete with ERp57 for its association with the specific binding site on actin surface.

Different actin conformational states modulate the nuclear ERp57/ß-actin complex. To better understand the mecha-

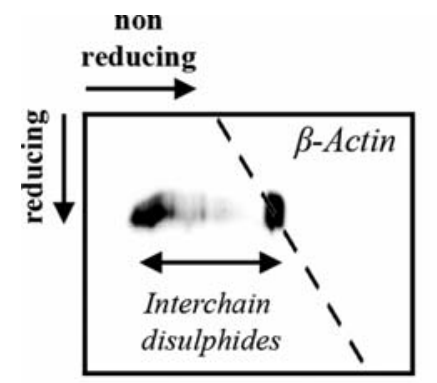

A2780

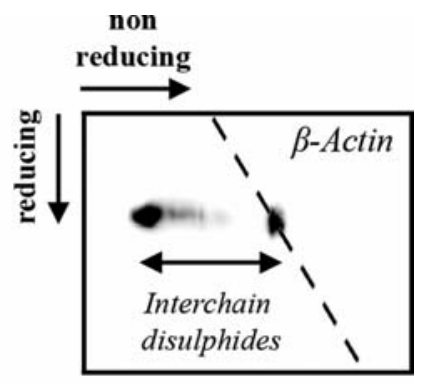

A2780TC1
Figure 5. Cysteine oxidative status of $\beta$-actin regulates the association with ERp57. Western blotting using anti-ß-actin monoclonal antibody after immunoprecipitation with anti-ERp57 antibody from total lysates. Cells were previously treated with NEM to prevent aspecific disulphide exchanges. Eluted proteins from the beads were subjected to 2-DE non-reduced/reduced analysis. Proteins lacking disulphide bonds migrate on the diagonal (gray line) because of the identical mobility in both dimensions. Proteins that contain intrachain disulphide bonds are more compact and run above the diagonal; proteins that form interchain disulphide-linked complexes run below the diagonal.

nisms related to ERp57/ß-actin interaction in the nuclear compartment, we used two different anti-actin antibodies: the 1C7 antibody raised against a chemically cross-linked actin dimer, called lower dimer (43), and the $2 \mathrm{G} 2$ antibody able to recognise a profilin-actin complex with poly $\mathrm{A} / \mathrm{U}$ from calfthyme that recognizes an epitope of actin that is exposed when in complex with profilin, specific for nuclear actin (44). As shown in Fig. 4C, both the 1C7 and 2G2 antibodies were able to immunoprecipitate $\beta$-actin in nuclear fractions obtained from paclitaxel-resistant A2780TC1 and sensitive A2780 cells, but actin association with ERp57 was observed only when nuclear lysates from A2780 cells were used. Even if we cannot exclude the participation of the other isotypes of actin to this complex, $\beta$-actin has been demonstrated to be the major isotype in the nucleus (39). These data indicate that specific conformational states of actin are involved in the formation of the ERp57 nuclear complex. Furthermore, as shown in Fig. 4C, the occurrence of the $\beta$-actin participation in the protein complex is modulated by paclitaxel treatment.

Disulphide bonds modulate $\beta$-actin association with ERp57. The implication of actin cysteine residues has been described in the regulation of actin conformational states in which the formation of a sulfinic acid (at C272) and inter-disulphide bridges via C374 play a role (42). Considering ERp57 reductase activity, we evaluated the possible involvement of the cysteine oxidation status of $B$-actin in the interaction with ERp57. A2780 and A2780TC1 cells were pre-treated with NEM in order to prevent disulphide exchange and cell lysates subjected to immunoprecipitation with anti-ERp57 antibody. Eluted proteins from immunoprecipitation were subjected to 2-DE non-reduced/reduced SDS-PAGE analysis with the first dimension carried out under non-reducing conditions to separate mixed disulphide complexes and the second dimension run upon reducing conditions to resolve the mixed disulphides according to their individual size followed by Western blotting with the antibody specific for $\beta$-actin. We did not perform any cellular fractioning in order to preserve mixed disulphide complexes. The detection of a horizontal 
line below the diagonal corresponding to inter-chain disulphide linked complexes (Fig. 5) indicates that redox states of B-actin cysteine residues are implicated in the interaction with ERp57. However, due to the complex combinatorial character of the actin cytoskeleton, treatment with NEM very likely influenced a large number of processes, including also those directly associated with the actin cytoskeleton, where ERp57 has already been shown to play a role (3). For this reason, with this experimental approach we can demonstrate the involvement of actin cysteine residues in association with ERp57 and suggest their possible role also in the nuclear compartment.

\section{Discussion}

ERp57 has recently been suggested to represent a potential chemoresistance-specific biomarker in ovarian cancer (3-5). ERp57 is a member of the protein disulphide isomerases family that consists of four domains named $a, b, b^{\prime}$ and $a^{\prime}$ with a and a' containing the thioredoxin-like active site sequence WCGHCK, whereas $b$ and $b^{\prime}$ are redox inactive (10). ERp57 acts as a chaperone and is involved in the proper folding and formation and reshuffling of the disulfide bridges of newly synthesized proteins in the ER as well as glycoprotein maturation $(45,46)$. ERp57 has a role in conferring resistance to apoptosis under hypoxia and a potential role in the oxygen-sensing apparatus, thus showing clinical applications to endoplasmic reticulum stress and cancer (47). In fact, the microenvironment of tumours, due to glucose deprivation and hypoxic conditions caused by poor vascularization, represents physiological ER stress which induces the unfolded protein response, where ERp57 plays an important role. In particular, in recent studies we observed that the most significant global functions associated with the highest number of changing proteins in paclitaxel-sensitive compared to paclitaxel-resistant ovarian cancer cell lines were those related to stress response and chaperones $(3,4)$. We have also demonstrated that TUBB3, which has an important role as a clinical marker of drug resistance and poor prognosis in human cancer $(14,15)$, is functionally inserted in a survival pathway able to adapt cells to a microenvironment featured by low oxygen level and poor nutrient supply since it interacts with several chaperones and proteins that catalyze protein folding (48), and in particular with ERp57 (3). We have suggested that ERp57, through its disulphide isomerase activity, might have a role in the proper folding and compartmentalization of TUBB3 in response to paclitaxel treatment. Though mainly localised in the ER, ERp57 has been detected in the cytosol, where it participates to signal transduction and transcription regulation by activation of STAT3 (11) and in association with the cytoskeleton (3), and in the nucleus, where it influences the DNA binding of transcription factors or of structural nuclear proteins $(49,50)$ and is involved in the cellular response to drug treatment $(3,13,51)$.

Twenty-four amino acids at the N-terminal hydrophobic region are known to target ERp57 to ER for synthesis at the ER membrane and translocation into the ER lumen. In addition, ERp57 contains putative nuclear localization (494KPKKKKK500) and ER retention (502QEDL505) signals. It appears that ERp57 contains a single nuclear localization signal (NLS) since no other NLS was found by sequence analysis and deletion or mutation of NLS led to complete loss of entry of mutant ERp57 in the nucleus (52). It still remains to be determined if the ERp57 subcellular localization and activity is regulated by phosphorylation, even if a study demonstrated that cytosolic ERp57 is phosphorylated at serine 150 (28).

In this study, we provide further evidence about the cellular distribution of ERp57 and its involvement in particular nuclear functions. Our data indicate that ERp57 within the nucleus exists in its phosphorylated isoform and associates with a nuclear complex containing Nucleolin, Nucleophosmin, Vimentin, Aurora kinase $C$ and $\beta$-actin. Nucleolin seems to be over-expressed in highly proliferative cells and is involved in many aspect of gene expression: chromatin remodeling, DNA recombination and replication, RNA transcription by RNA polymerase I and II, rRNA processing, mRNA stabilisation, cytokinesis and apoptosis (8). Nucleophosmin is an abundantly expressed multifunctional nucleolar phosphoprotein involved in cell division and in the cellular response to genotoxic stress $(53,54)$. Both Nucleolin and Nucleophosmin have been described also as genotoxic stress-responsive RNAbinding proteins (31). Aurora kinase $\mathrm{C}$ belongs to a family of evolutionarily conserved serine/threonine kinases that have important functions in centrosome duplication, mitotic spindle assembly, chromosome condensation, chromosome biorientation on the spindle and chromosome segregation (34). Aurora kinases perform important functions during mitosis and hence their aberrant expression can lead to the cell transformation underlying cancer. In many tissues, Aurora kinase over-expression leads to genetic instability, which may cause cancer $(35,37,55)$. For this reason, the Aurora kinases are currently one of the most interesting targets for cancer therapy. Moreover, recent studies demonstrated that Aurora kinase inhibitors synergize with microtubule targeted agents to induce apoptosis in several tumor cell lines $(56,57)$ and are potent killers of taxane-sensitive and -resistant ovarian cancer cells (58). Interestingly, our results show that ERp57 in the nucleus is phosphorylated and suggest the involvement of a specific kinase and/or phosphatase activity in the modulation of ERp57 subcellular distribution. We may speculate that Aurora kinase $\mathrm{C}$ very likely plays a role in the modulation of ERp57 phosphorylation and nuclear compartmentalisation. Vimentin is a type III intermediate filament protein that has been recently characterised as a chromosome fibrous protein (59) and as a protein involved in the correct segregation of the filament during mitosis (38). It has also been found to be a mitotic substrate of an O-GlcNac/phosphate complex formed by Aurora kinase B (AKB), protein phosphatase I (PPI), O-GlcNAc transferase (OGT) and O-GlcNAcase (OGA) (60). Interestingly, Vimentin has also been identified among the proteins differentially expressed in benign and malignant ovarian tumours when compared to borderline ovarian tumours (61). Moreover, in a previous report, we identified Vimentin among the protein species able to interact with TUBB3 (48). Actin is a major component of the cytoskeleton and plays a critical role in all eukaryotic cells. The actin cytoskeleton functions in diverse cellular processes, including cell motility, contractility, mitosis and cytokinesis, intracellular transport, endocytosis and secretion 
$(16,17)$. In addition to this mechanical function, actin has been suggested to play a role in centrosome clustering and chromosome congression and to have an important function for successful mitosis of cells carrying centrosome amplification (40). It is worth noting that defects in centrosome clustering correlate with aneuploidy and malignant behaviour in several human tumors. These pieces of evidence strengthen the hypothesis on a role of ERp57 in the spindle assembly checkpoint, in the regulation of chromosomal segregation and genome integrity and its involvement in cancer development.

Mechanical linkages between chromatidis and microtubules are crucially important for spindle assembly and the alteration or disruption of kinetochore-microtubule attachment leads to mitotic spindle disorganization. Actin has been shown to have a role in the control of spindle polarity in association with microtubules (41). Interestingly, it has been recently demonstrated that microtubule stabilizing agents, such as paclitaxel, epothilone $\mathrm{B}$ and discodermolide, but not the destabilizing agents, like colchicines, nocodazolo and vinblastine, induce aberrant mitosis through multipolar spindle formation and aneuploidy $(62,63)$.

In particular, here we describe the involvement of $\beta$-actin association with the ERp57 nuclear complex in paclitaxel resistance. ERp57 interaction with B-actin was characterised by $1-\mathrm{DE}$ and $2-\mathrm{DE}$ analysis and by sub-cellular fractioning and immunoprecipitation. These analysis demonstrate that ERp57 forms a complex with $B$-actin through disulphide bonds and associates within the nucleus with specific conformational states of actin, as shown by immunoprecipitation analysis performed using the $1 \mathrm{C} 7$ and $2 \mathrm{G} 2$ anti-actin antibodies, raised, respectively, against a cross-linked actin dimer called lower dimer, and a profilin-actin complex. It is worth noting that these two antibodies recognize particular actin conformations that specifically contribute to its function in the nucleus $(43,44)$. In particular, $2 \mathrm{G} 2$ reactivity has been shown to be consistent with the presence of actin-profilin complexes in the nucleus, while $1 \mathrm{C} 7$ recognizes actin in complex with other factor or, alternatively, an actin population that has undergone post-translational modification. Interestingly, the interaction of ERp57 with these specific actin conformations was not observable in paclitaxel-resistant cells.

Actin supramolecular organization, location and function are determined by diverse repertoire of actin conformations and oligomer and polymer forms beyond monomeric $\mathrm{G}$ (globular)-actin and polymeric $\mathrm{F}$ (filamentous)-actin $(64,65)$. It has been shown that distinct actin conformations and/or structures are present in the nucleus and in the cytoplasm and that their distribution varies in response to external signals. In general, $B$-actin is the isotype localised in the nucleus (39). A plethora of actin binding proteins arranges and stabilises actin into various suprastructures required for its functions and regulates its cellular distribution in response to external signals. To date, almost one hundred of actin-binding proteins have been identified (66). These proteins, under the control of specific signalling pathways, regulate the forms and functions of actin in the cell, including the nucleocytoplasmic translocation of actin. There is also increasing evidence that posttranslational modifications, including glutathionylation (67), nitration (68), nitrosylation (69) and arginylation (70), play important roles in regulating the cellular functions of actin. More recently it has been observed that sumoylation is required for the nuclear localization of actin (71). It is possible that paclitaxel treatment may regulate actin function by altering its posttranslational status and the affinity with its direct actin binding proteins or modulating the protein expression level of some actin binding proteins and, consequently, the structure within the nucleus, and this may decrease also its binding activity to the ERp57 nuclear complex.

Understanding the molecular mechanisms involved in ovarian cancer and in particular the molecular mechanism involved in ERp57/ß-actin association related to the specific nuclear actin conformation states in ovarian cancer cells might favour the development of novel therapeutic approaches to overcome mitotic defects observed in cancer cells and chemoresistance occurrence.

\section{Acknowledgments}

This work was partially supported by MIUR (Programma Triennale Ricerca, decreto 1558). We thank Dr Cristiano Ferlini for providing us with A2780 and A2780TC1 cells and Dr Pasquale Fasanaro for his technical assistance.

\section{References}

1. Parkin DM, Bray F, Ferlay J and Pisani P: Global cancer statistics, 2002. CA Cancer J Clin 55: 74-108, 2005.

2. Fojo $\mathrm{T}$ and Menefee $\mathrm{M}$ : Mechanisms of multidrug resistance: the potential role of microtubule-stabilizing agents. Ann Oncol 18 (Suppl. 5): V3-V8, 2007.

3. Cicchillitti L, Di Michele M, Urbani A, Ferlini C, Donati MB, Scambia G and Rotilio D: Comparative proteomic analysis of paclitaxel sensitive A2780 epithelial ovarian cancer cell line and its resistant counterpart A2780TC1 by 2D-DIGE: the role of ERp57. J Proteome Res 8: 1902-1912, 2009.

4. Di Michele M, Della Corte A, Cicchillitti L, Del Boccio P, Urbani A, Ferlini C, Scambia G, Donati MB and Rotilio D: A proteomic approach to paclitaxel chemoresistance in ovarian cancer cell lines. Biochim Biophys Acta 1794: 225-236, 2009.

5. Bernardini M, Lee CH, Beheshti B, Prasad M, Albert M, Marrano P, Begley H, Shaw P, Covens A, Murphy J, Rosen B, Minkin S, Squire JA and Macgregor PF: High-resolution mapping of genomic imbalance and identification of gene expression profiles associated with differential chemotherapy response in serous epithelial ovarian cancer. Neoplasia 7: 603$613,2005$.

6. Otsu M, Urade R, Kito M, Omura F and Kikuchi M: A possible role of ER-60 protease in the degradation of misfolded proteins in the endoplasmic reticulum. J Biol Chem 270: 14958-14961, 1995.

7. Murthy MS and Pande SV: A stress-regulated protein, GRP58, a member of thioredoxin superfamily, is a carnitine palmitoyltransferase isoenzyme. Biochem J 304: 31-34, 1994.

8. Srivastava M and Pollard HB: Molecular dissection of nucleolin's role in growth and cell proliferation: new insights. FASEB J 13: 1911-1922, 1999.

9. Hirano N, Shibasaki F, Sakai R, Tanaka T, Nishida J, Yazaki Y, Takenawa T and Hirai H: Molecular cloning of the human glucose-regulated protein ERp57/GRP58, a thiol-dependent reductase. Identification of its secretory form and inducible expression by the oncogenic transformation. Eur J Biochem 234: 336-342, 1995.

10. Freedman RB, Hirst TR and Tuite MF: Protein disulphide isomerase: building bridges in protein folding. Trends Biochem Sci 19: 331-336, 1994.

11. Ndubuisi MI, Guo GG, Fried VA, Etlinger JD and Sehgal PB: Cellular physiology of STAT3: Where's the cytoplasmic monomer? J Biol Chem 274: 25499-25509, 1999.

12. Wyse B, Ali $\mathrm{N}$ and Ellison DH: Interaction with grp58 increases activity of the thiazide-sensitive $\mathrm{Na}-\mathrm{Cl}$ cotransporter. Am J Physiol Renal Physiol 282: F424-F430, 2002. 
13. Krynetski EY, Krynetskaia NF, Bianchi ME and Evans WE: A nuclear protein complex containing high mobility group proteins B1 and B2, heat shock cognate protein 70, ERp60, and glyceraldehyde-3-phosphate dehydrogenase is involved in the cytotoxic response to DNA modified by incorporation of anticancer nucleoside analogues. Cancer Res 63: 100-106, 2003.

14. Ferrandina G, Zannoni GF, Martinelli E, Paglia A, Gallotta V, Mozzetti S, Scambia G and Ferlini C: Class III beta-tubulin overexpression is a marker of poor clinical outcome in advanced ovarian cancer patients. Clin Cancer Res 12: 2774-2779, 2006.

15. Cochrane DR, Spoelstra NS, Howe EN, Nordeen SK and Richer JK: MicroRNA-200c mitigates invasiveness and restores sensitivity to microtubule-targeting chemotherapeutic agents. Mol Cancer Ther (In press).

16. Chen H, Bernstein BW and Bamburg JR: Regulating actinfilament dynamics in vivo. Trends Biochem Sci 25: 19-23, 2000 .

17. Carlier MF, Le Clainche C, Wiesner S and Pantaloni D: Actinbased motility: from molecules to movement. Bioessays 25 : 336-345, 2003

18. Sotiropoulos A, Gineitis D, Copeland J and Treisman R: Signalregulated activation of serum response factor is mediated by changes in actin dynamics. Cell 98: 159-169, 1999.

19. Grummt I: Actin and myosin as transcription factors. Curr Opin Genet Dev 16: 191-196, 2006.

20. Lane NJ: Intranuclear fibrillar bodies in actinomycin D-treated oocytes. J Cell Biol 40: 286-291, 1969.

21. Olave IA, Reck-Peterson SL and Crabtree GR: Nuclear actin and actin-related proteins in chromatin remodeling. Annu Rev Biochem 71: 755-781, 2002.

22. De Lanerolle P, Johnson T and Hofmann WA: Actin and myosin I in the nucleus: what next? Nat Struct Mol Biol 12: 742-746, 2005

23. Pederson $\mathrm{T}$ and Aebi U: Nuclear actin extends, with no contraction in sight. Mol Biol Cell 16: 5055-5060, 2005.

24. Percipalle $\mathrm{P}$ and Visa N: Molecular functions of nuclear actin in transcription. J Cell Biol 172: 967-971, 2006.

25. Sjolinder M, Bjork P, Soderberg E, Sabri N, Farrants AK and Visa N: The growing pre-mRNA recruits actin and chromatinmodifying factors to transcriptionally active genes. Genes Dev 19: 1871-1884, 2005.

26. Ferlini C, Raspaglio G, Mozzetti S, Distefano M, Filippetti F, Martinelli E, Ferrandina G, Gallo D, Ranelletti FO and Scambia G: Bcl-2 down-regulation is a novel mechanism of paclitaxel resistance. Mol Pharmacol 64: 51-58, 2003.

27. Klappa P, Stromer T, Zimmermann R, Ruddock LW and Freedman RB: A pancreas-specific glycosylated protein disulphide-isomerase binds to misfolded proteins and peptides with an interaction inhibited by oestrogens. Eur J Biochem 254: $63-69,1998$

28. Kita K, Okumura N, Takao T, Watanabe M, Matsubara T, Nishimura $\mathrm{O}$ and Nagai K: Evidence for phosphorylation of rat liver glucose-regulated protein 58, GRP58/ERp57/ER-60, induced by fasting and leptin. FEBS Lett 580: 199-205, 2006.

29. Tokutomi Y, Arak, N, Kataoka K, Yamamoto E and KimMitsuyama S: Oxidation of Prx2 and phosphorylation of GRP58 by angiotensin II in human coronary smooth muscle cells identified by 2D-DIGE analysis. Biochem Biophys Res Commun 364: 822-830, 2007

30. Storck S, Shukla M, Dimitrov S and Bouvet P: Functions of the histone chaperone nucleolin in diseases. Subcell Biochem 41: 125-144, 2007

31. Yang C, Maiguel DA and Carrier F: Identification of nucleolin and nucleophosmin as genotoxic stress-responsive RNA-binding proteins. Nucleic Acids Res 30: 2251-2260, 2002

32. Kimura M, Matsuda Y, Yoshioka T and Okano Y: Cell cycledependent expression and centrosome localization of a third human aurora/Ipl1-related protein kinase, AIK3. J Biol Chem 274: 7334-7340, 1999

33. Li X, Sakashita G, Matsuzaki H, Sugimoto K, Kimura K Hanaoka F, Taniguchi H, Furukawa K and Urano, T: Direct association with inner centromere protein (INCENP) activates the novel chromosomal passenger protein, Aurora-C. J Biol Chem 279: 47201-47211, 2004

34. Vader G and Lens SM: The Aurora kinase family in cell division and cancer. Biochim Biophys Acta 1786: 60-72, 2008.

35. Tao X, Chon HS, Fu S, Kavanagh JJ and Hu W: Update on aurora kinase inhibitors in gynecologic malignancies. Recent Pat Anticancer Drug Discov 3: 162-177, 2008.
36. Macarulla T, Ramos FJ and Tabernero J: Aurora kinase family: a new target for anticancer drug. Recent Pat Anticancer Drug Discov 3: 114-122, 2008.

37. Zhou H, Kuang J, Zhong L, Kuo WL, Gray JW, Sahin A, Brinkley BR and Sen S: Tumour amplified kinase STK15/BTAK induces centrosome amplification, aneuploidy and transformation. Nat Genet 20: 189-193, 1998.

38. Izawa I and Inagaki M: Regulatory mechanisms and functions of intermediate filaments: a study using site- and phosphorylation state-specific antibodies. Cancer Sci 97: 167-174, 2006.

39. Jonsson AP, Aissouni Y, Palmberg C, Percipalle P, Nordling E, Daneholt B, Jornvall $\mathrm{H}$ and Bergman T: Recovery of gel-separated proteins for in-solution digestion and mass spectrometry. Anal Chem 73: 5370-5377, 2001.

40. Kwon M, Godinho SA, Chandhok NS, Ganem NJ, Azioune A, Thery M and Pellman D: Mechanisms to suppress multipolar divisions in cancer cells with extra centrosomes. Genes Dev 22: 2189-2203, 2008

41. Xu FL and Saunders WS: Actin and microtubules: working together to control spindle polarity. Cancer Cell 14: 197-199, 2008.

42. Lassing I, Schmitzberger F, Bjornstedt M, Holmgren A, Nordlund P, Schutt CE and Lindberg U: Molecular and structural basis for redox regulation of beta-actin. J Mol Biol 370: 331-348, 2007.

43. Schoenenberger CA, Buchmeier S, Boerries M, Sutterlin R, Aebi U and Jockusch BM: Conformation-specific antibodies reveal distinct actin structures in the nucleus and the cytoplasm. J Struct Biol 152: 157-168, 2005.

44. Gonsior SM, Platz S, Buchmeier S, Scheer U, Jockusch BM and Hinssen H: Conformational difference between nuclear and cytoplasmic actin as detected by a monoclonal antibody. J Cell Sci 112: 797-809, 1999.

45. Frenkel Z, Shenkman M, Kondratyev M and Lederkremer GZ: Separate roles and different routing of calnexin and ERp57 in endoplasmic reticulum quality control revealed by interactions with asialoglycoprotein receptor chains. Mol Biol Cell 15: 2133-2142, 2004

46. Molinari M and Helenius A: Glycoproteins form mixed disulphides with oxidoreductases during folding in living cells. Nature 402: 90-93, 1999.

47. Ni M and Lee AS: ER chaperones in mammalian development and human diseases. FEBS Lett 581: 3641-3651, 2007.

48. Cicchillitti L, Penci R, Di Michele M, Filippetti F, Rotilio D, Donati MB, Scambia G and Ferlini C: Proteomic characterization of cytoskeletal and mitochondrial class III beta-tubulin. Mol Cancer Ther 7: 2070-2079, 2008.

49. Coppari S, Altieri F, Ferraro A, Chichiarelli S, Eufemi M and Turano C: Nuclear localization and DNA interaction of protein disulfide isomerase ERp57 in mammalian cells. J Cell Biochem 85: 325-333, 2002

50. Grillo C, D'Ambrosio C, Scaloni A, Maceroni M, Merluzzi S, Turano C and Altieri F: Cooperative activity of Ref-1/APE and ERp57 in reductive activation of transcription factors. Free Radic Biol Med 41: 1113-1123, 2006.

51. Celli CM and Jaiswal AK: Role of GRP58 in mitomycin Cinduced DNA cross-linking. Cancer Res 63: 6016-6025, 2003.

52. Adikesavan AK, Unni E and Jaiswal AK: Overlapping signal sequences control nuclear localization and endoplasmic reticulum retention of GRP58. Biochem Biophys Res Commun 377: 407-412, 2008.

53. Amin MA, Matsunaga S, Uchiyama S and Fukui K: Nucleophosmin is required for chromosome congression, proper mitotic spindle formation, and kinetochore-microtubule attachment in HeLa cells. FEBS Lett 582: 3839-3844, 2008.

54. Li J, Zhang X, Sejas DP, Bagby GC and Pang Q: Hypoxiainduced nucleophosmin protects cell death through inhibition of p53. J Biol Chem 279: 41275-41279, 2004.

55. Kollareddy M, Dzubak P, Zheleva D and Hajduch M: Aurora kinases: structure, functions and their association with cancer. Biomed Pap Med Fac Univ Palacky Olomouc Czech Repub 152: 27-33, 2008

56. VanderPorten EC, Taverna P, Hogan JN, Ballinger MD, Flanagan WM and Fucini RV: The Aurora kinase inhibitor SNS-314 shows broad therapeutic potential with chemo+therapeutics and synergy with microtubule-targeted agents in a colon carcinoma model. Mol Cancer Ther 8: 930-939, 2009.

57. Curry J, Angove H, Fazal L, Lyons J, Reule M, Thompson N and Wallis N: Aurora B kinase inhibition in mitosis: strategies for optimising the use of aurora kinase inhibitors such as AT9283. Cell Cycle 8: 1921-1929, 2009. 
58. Scharer CD, Laycock N, Osunkoya AO, Logani S, McDonald JF, Benigno BB and Moreno CS: Aurora kinase inhibitors synergize with paclitaxel to induce apoptosis in ovarian cancer cells. J Transl Med 6: 79, 2008.

59. Fukui K and Uchiyama S: Chromosome protein framework from proteome analysis of isolated human metaphase chromosomes. Chem Rec 7: 230-237, 2007.

60. Slawson C, Lakshmanan T, Knapp S and Hart GW: A mitotic GlcNAcylation/phosphorylation signaling complex alters the posttranslational state of the cytoskeletal protein vimentin. Mol Biol Cell 19: 4130-4140, 2008.

61. Bengtsson S, Krogh M, Szigyarto CA, Uhlen M, Schedvins K, Silfversward C, Linder S, Auer G, Alaiya A and James P: Large-scale proteomics analysis of human ovarian cancer for biomarkers. J Proteome Res 6: 1440-1450, 2007.

62. Chen JG and Horwitz SB: Differential mitotic responses to microtubule-stabilizing and -destabilizing drugs. Cancer Res 62 : 1935-1938, 2002.

63. Chen JG, Yang CP, Cammer M and Horwitz SB: Gene expression and mitotic exit induced by microtubule-stabilizing drugs. Cancer Res 63: 7891-7899, 2003.

64. Pederson T: As functional nuclear actin comes into view, is it globular, filamentous, or both? J Cell Biol 180: 1061-1064, 2008.

65. Schleicher M and Jockusch BM: Actin: its cumbersome pilgrimage through cellular compartments. Histochem Cell Biol 129: 695-704, 2008.
66. Dos Remedios CG, Chhabra D, Kekic M, Dedova IV, Tsubakihara M, Berry DA and Nosworthy NJ: Actin binding proteins: regulation of cytoskeletal microfilaments. Physiol Rev 83: 433-473, 2003.

67. Wang J, Tekle E, Oubrahim H, Mieyal JJ, Stadtman ER and Chock PB: Stable and controllable RNA interference: investigating the physiological function of glutathionylated actin. Proc Natl Acad Sci USA 100: 5103-5106, 2003.

68. Aslan M, Ryan TM, Townes TM, Coward L, Kirk MC, Barnes S, Alexander CB, Rosenfeld SS and Freeman BA: Nitric oxidedependent generation of reactive species in sickle cell disease. Actin tyrosine induces defective cytoskeletal polymerization. J Biol Chem 278: 4194-4204, 2003.

69. Thom SR, Bhopale VM, Mancini DJ and Milovanova TN: Actin S-nitrosylation inhibits neutrophil beta2 integrin function. J Biol Chem 283: 10822-10834, 2008.

70. Karakozova M, Kozak M, Wong CC, Bailey AO, Yates JR III, Mogilner A, Zebroski $\mathrm{H}$ and Kashina A: Arginylation of betaactin regulates actin cytoskeleton and cell motility. Science 313: 192-196, 2006.

71. Hofmann WA, Arduini A, Nicol SM, Camacho CJ, Lessard JL, Fuller-Pace FV and De Lanerolle P: SUMOylation of nuclear actin. J Cell Biol 186: 193-200, 2009. 